\title{
Integration of Religion and Spirituality Into Trauma Psychotherapy: An Example in Sufism?
}

\author{
Walid Khalid Abdul-Hamid \\ Centre for Psychiatry, Barts and the London School of Medicine and Dentistry, \\ Queen Mary University of London, United Kingdom \\ Linden Centre, Broomfield, Chelmsford, Essex, United Kingdom \\ Jamie Hacker Hughes \\ Veterans and Families Institute, Anglia Ruskin University, \\ Chelmsford, Essex, United Kingdom
}

\begin{abstract}
Bilateral stimulation (BLS) is of significant importance to eye movement desensitization and reprocessing (EMDR) therapy. Eye movements seem to be the most effective form of BLS in EMDR. A brief summary of the cultural applicability of EMDR is provided, and research which showed the value of incorporating religion and/or spirituality into psychotherapy is highlighted. Islamic Sufism, in common with other traditional religions, has long been known to have a psychotherapeutic perspective and has been used over time to help people to overcome trauma and stress. This article argues that the ritual movements associated with the Sufi Dhikr may involve a form of BLS and that this might underline some of the therapeutic effectiveness of Dhikr and Sufism. The authors recommend investigating if the Sufi Dhikr element could be incorporated into a modified EMDR protocol. We anticipate that this would give EMDR an even wider and more popular acceptance in the Middle East and the Muslim world.
\end{abstract}

Keywords: eye movement desensitization and reprocessing (EMDR); Dhikr; Sufism; spiritual therapy; culture; trauma therapy

$\mathbf{T}$ he importance of spirituality in mental health, particularly when related to trauma, is a welldocumented and researched area. The fact that many ethnic and religious groups prefer to see spiritual therapists rather than mental health professionals makes it important to incorporate spiritual traditions into mental health interventions to make them more acceptable to faith-based communities.

\section{Eye Movement Desensitization and Reprocessing}

Eye movement desensitization and reprocessing (EMDR) was developed by the American psychologist Francine Shapiro who introduced this new therapy into professional and clinical practice in 1989 with her seminal randomized control study (Shapiro, 1989). Meta-analyses of trials (38 controlled studies, of which 15 were randomized clinical trials) suggested that both trauma-focused cognitive behavioral therapy (CBT) and EMDR were equally effective in reducing symptoms of posttraumatic stress disorder (PTSD; Bisson, Roberts, Andrew, Cooper, \& Lewis, 2013; Bradley, Greene, Russ, Dutra, \& Westen, 2005). EMDR has been recognized internationally as an efficacious treatment for PTSD. The World Health Organization's (WHO, 2013) 2013 Guidelines for the Management of Conditions Specifically Related to Stress states that EMDR is as effective as CBT and that EMDR does not require detailed descriptions of the event, direct challenging of clients' beliefs, extended exposure, and homework, all of which are needed in CBT therapy.

A recent study, funded by the National Institute of Mental Health in the United States found that eight sessions of EMDR therapy were superior to 8 weeks of treatment with fluoxetine (van der Kolk et al., 2007). The superiority of EMDR in the treatment of PTSD symptoms continued even after termination of the intervention. Benefits for the EMDR participants 
were maintained after therapy, whereas the fluoxetinetreated group became more symptomatic. Tests at follow-up showed that $91 \%$ of the EMDR group no longer had PTSD compared to $72 \%$ of the fluoxetine group.

EMDR therapy is based on Shapiro's (2001) adaptive information processing (AIP) theory, which postulates that PTSD is caused by the presence of unprocessed memories of the traumatic event. The flashbacks; nightmares; and intrusive images, thoughts, and emotions of PTSD are understood to result from the activation of maladaptively stored memories (Shapiro, 2007). EMDR therapy consists of eight phases of treatment based on standardized procedures, using a three-pronged model to address (a) past events that constitute the etiology of the problem, (b) present disturbance, and (c) future action. During the reprocessing of related memories, the client engages in dual attention, focusing on the memory components while engaging in bilateral stimulation (BLS). BLS may be horizontal eye movements (the clients' eyes follow the therapist's finger movements), tactile stimulation by bilateral tapping, or auditory tones alternating between the left and right ears (Shapiro, 2012).

Eye movements have been found to make a significant contribution to treatment outcome in EMDR (Lee \& Cuijpers, 2013). Repeated research findings cited by Shapiro (2014) show that eye movement is superior to other forms of BLS in EMDR (Barrowcliff, Gray, Freeman, \& MacCulloch, 2004; Christman, Garvey, Propper, \& Phaneuf, 2003; Davidson \& Parker, 2001; Propper, Pierce, Geisler, Christman, \& Bellorado, 2007; van den Hout et al., 2012).

More than 20 randomized studies have identified the various effects of eye movements. These include

- Reducing the emotionality and/or vividness of memories (van den Hout \& Engelhard, 2012). Multiple research studies have shown that this degradation of memory quality results from working memory effects caused by EMDR's dual attention component in which the client focuses on the memory while simultaneously engaging in eye movements.

- Facilitating episodic memory (Christman et al., 2003) and associative thinking (Kuiken, Chudleigh, \& Racher, 2010). It has been theorized that this effect is caused by either the degradation of the distressing memory (Maxfield, Melnyk, \& Hayman, 2008) and/or physiological effects similar to those in rapid eye movement (REM) sleep.
- Physiological changes (Elofsson, von Schèele, Theorell, \& Söndergaard, 2008) such as activation of the cholinergic and inhibition of the sympathetic systems. These activities are similar to the changes that happen during REM sleep.

\section{Cultural Applications of EMDR}

EMDR therapy has been widely used around the world, with practitioners in North, South, and Central Americas; Europe; Middle East; Africa; Asia; and Australia, all trained in and using EMDR (Maxfield, 2014). Nevertheless, adapting the cultural and spiritual roots of this effective therapy will, it is argued, further enrich it as a therapeutic modality and make it more accessible to wider populations throughout the world. Furthermore, although the AIP theory makes EMDR a relatively culture-free technique, it is based on modern Western concepts (i.e., the storage of memory in brain networks) and may not be easily understandable or appealing to those with different educations and/or world views.

A large study in the United States found that the use of mental health by people of Latin American origin is greatly influenced by cultural factors. The author recommended matching mental health services to the cultural characteristics of populations and not the other way round (Alegría et al., 2007). During the horrific war in the Democratic Republic of Congo during the years 1996-2007, a research group conducted an evaluation study of the use of an intervention program carried out by trained local staff. Results showed that using local staff not only reduced the cost but also increased the use of the program, particularly by trauma victims and sexual assault victims. Training local staff enhances cultural awareness and the provision of appropriate service for the diagnosis and treatment of trauma victims.

The authors have been providing teaching and supervision of EMDR to 30 Middle East psychological health professionals in Istanbul in a project organized by the Humanitarian Assistance Programme (HAP) of the EMDR Association UK and Ireland. Following the three parts of the EMDR training, ongoing supervision is conducted through Skype to review the trainees' therapy with their Middle Eastern clients. Our experiences have convinced us that making more parallels between EMDR procedures and local religious and cultural traditions in the Middle East helped to improve the use, acceptability, and effectiveness of therapy in these clients, confirming Gordon's (2006) similar finding in Gaza. 


\section{Integration of Religion and Spirituality Into Psychotherapy}

\section{The Spiritual Dimension of Mental Health}

It was in 1984 that the 37th Assembly of the WHO recognized the spiritual dimension of mental health as a significant component of mental health particularly in the developing world (Basu, 1995). This is because spirituality and religion constitute important aspects of the person's resilience and ability to cope with trauma and stress (Abdul-Hamid, 2011; Dein, 2006). This fact, in its turn, has led many psychotherapeutic movements to incorporate religion and spirituality into their therapeutic process (Nizamie, Katshu, \& Uvais, 2013).

Research has shown that spirituality is a protective factor against mental health disorders caused by traumatic events (Dervic, Grunebaum, Burke, Mann, \& Oquendo, 2006; Hipolito et al., 2014; Meadows, Kaslow, Thompson, \& Jurkovic, 2005; Moreira-Almeida, Neto, \& Koenig, 2006; Wong, Rew, \& Slaikeu, 2006; Yoon \& Lee, 2007). Spirituality can also protect trauma sufferers from depression and suicide by instilling hope into the sufferers (Gail, Basque, Damasceno-Scott, \& Vardy, 2007). This protective function of spirituality seems to be related mainly to the empowerment of trauma sufferers that enables posttraumatic growth and recovery (Johnson, Worell, \& Chandler, 2005).

Many recent studies have suggested that people from non-Western cultures tend to use traditional and spiritual therapies rather than Western models of explanation and treatment of mental illness. This is applicable to cultures overseas where up to $80 \%$ of people who suffer mental health problems consult a traditional healer rather than a mental health professional (Al-Faris, 2000; Saeed, Gater, Hussain, \& Mubbashar, 2000). A similar trend was observed in ethnic minorities in Europe (Johnsdotter, Ingvarsdotter, Ostman, \& Carlbom, 2011).

This demonstrates the importance of making mental health interventions acceptable to faith-based communities. Trials of the augmentation of CBT with spiritual and religious beliefs have clearly shown that this increases the effectiveness of this therapy in Western and non-Western cultures (Azhar, Varma, \& Dharap, 1994, Propst, Ostrom, Watkins, Dean, \& Mashburn, 1992; Razali, Hasanah, Aminah, \& Sabramaniam, 1998).

As Nixon and Zangeneh (2012) put it, "Sufism and other wisdom traditions can be applied to psychotherapy" (p. 310). Razali et al. (1998) and Azhar et al. (1994) conducted separate study trials in
Malaysia and Pakistan. They found that adding aspects of Sufi therapy (as suggested by Ajmal, 1986) to the traditional CBT of Muslim patients made the therapy more effective for both depression and anxiety.

Using Spirituality as an Element in Trauma Therapy. Using spirituality as an element in trauma therapy is an expanding field. Calhoun, Cann, Tedeschi, and McMillan (2000) suggested that because trauma involves a loss of existential meaning, there is a significant role for religious beliefs in facilitating personal meaning and purpose of life in the growth that follows traumatic events.

There is anecdotal evidence that Sufi Dhikr has been used traditionally by people in Muslim areas such as Kashmir that people turn to Sufis for the treatment of the psychological problems resulting from trauma of war and natural disasters (Nickelsberg \& Matloff, 2009). Sufi spirituality can help the healing process after trauma by enhancing personal growth and giving a positive meaning to suffering that enhances growth and resilience in trauma situation (Joseph, 2009). The Sufi master (or teacher) can also play a role in meeting the client's developmental need in dealing with traumatic events that prevent growth (West, 2004).

Hipolito et al. (2014) concluded from their study that incorporating spirituality in trauma treatment programs enabled trauma-informed services to treat clients with the empowerment that spirituality gives to trauma sufferers. Also, during her psychological work or traumatized people in Gaza, Gordon (2006) found that using movements derived from the Sufi Dhikr helped to improve the acceptability and effectiveness of psychological work on trauma.

\section{Sufism}

Sufism is an Islamic religious philosophy and a type of mysticism with specific Muslim religious connotations (Nicholson, 1989). It is practiced all over the Muslim world, and Sufis have been considered as being those who have therapeutic power and healing and who often practice as traditional healers (Qutb, 1945, pp. 3-7). Around half of the 1.2 billion Muslims all over the world are either Sufis or consider themselves to be influenced by the Sufi tradition. Sufism has more adherents in countries such as India, Indonesia, Egypt, Morocco, French-speaking West Africa, Turkey, and some parts of Central Asia; that figure of about half makes sense (Tolson, 2008). Sufism has additional adherents in countries such as Iran and Saudi Arabia where Sufis were persecuted for centuries.

Arberry (1969) defined Sufism as "Asceticism . . . when warmed by spiritual emotion it converts into 
ardent fervour rejoicing in hardship and delighting in ecstatic experience" (p. 45). Vaughan-Lee described Sufis as "travelers, making the greatest of all journeys, the journey home. This is a journey that takes the Sufi into the depths of himself" (Vaughan-Lee, 1990, p. xv).

The Sufi Dhikr or service is usually practiced in a hall decorated with inscriptions of the names of Allah, the Prophet, and his four caliphs. The Sufi murids (students) dervishes arrange themselves into a circle within the hall and, facing the pir or shaikh (the teacher), they start chanting the name "Allah" or "Hoo" and, either sitting or standing, they all make simultaneous light head and body movements while chanting. The movement "consists in balancing themselves slowly from right to the left and from left to the right" (Brown, 1868, p. 218). This type of movement, which can be done with open or closed eyes may cause eye movement similar to that used in EMDR. Thus, Sahrwardi (1980) wrote, on Sama:

The soul's ear may open and gain the rupture of the address of eternity without beginning and of the "first covenant" that with one shaking the bird of the soul may shake from itself the dust of existence and the clamminess of impurities; and may, from the pollution of the heart, of lust and of the crowd of existence, become free. (p. 30)

As to the Sufi dervish, the word dervish is derived from the Persian language. Dar means door and vish is to beg. The universally acceptable meaning of the whole word is "those who beg from door to door" in reference to the poverty associated with mysticism. The Arabic and Turkish equivalent is faqir (Brown, 1868). There are 12 Sufi dervish orders. They all practice regular ritual Dhikr that include a dance or "a religious circular movement" (Brown, 1868, p. 217; Figure 1).

\section{Historical Development of Sufism}

The philosophy of Sufism was seen by some authors as being related to Christian Platonic mystical ecstasy (Farrukh, 1981). However, mysticism and ascetic piety were integral parts of early Islamic society. Pious Muslims, especially those who were poor, were typified by the largely Ahl al-Suffa (those who belong to the Sufa), the companions of Prophet Muhammad who, because of their poverty, were sheltering in a vestibule (Suffa) of the Mosque of Medina. When not teaching the principles of Islam, they were said to have devoted their time to study and worship. Abu Nasr al-Jahani,

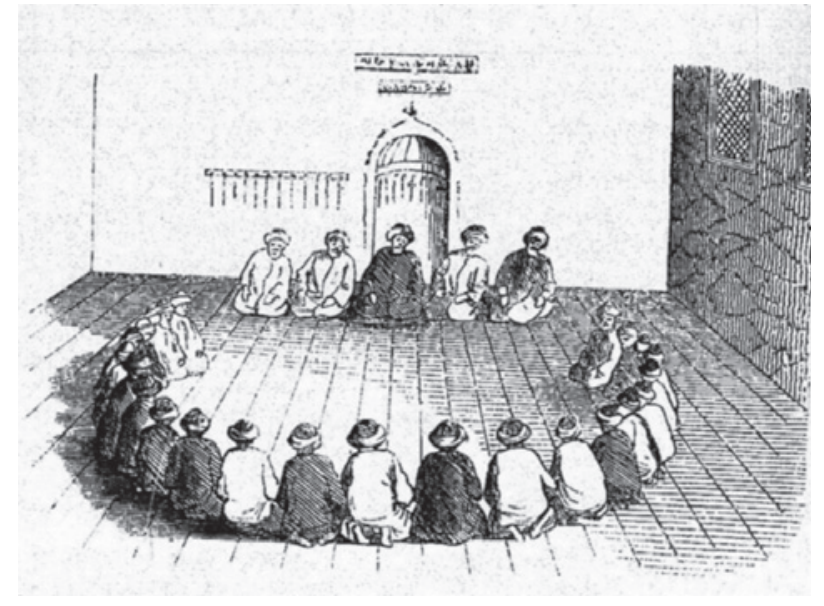

FIGURE 1. A Sufi Dhikr as illustrated in Brown (1868).

(d. $804 \mathrm{AD}$ ) was a member of the Ahl A-Suffa. He was, perhaps, illustrative of an original ascetic piety, which was later compounded with mysticism. These Ahl A-Suffa would sit in the back of the Prophet's Mosque in Medina and constituted the first groups of Sufis in Islam (Dols, 1992).

\section{Therapeutic Aspects of Sufism}

Some Muslim Sufi writers have suggested that the therapeutic effects of a Sufi Dhikr or Sufi ritual are caused by a state of "heightened consciousness" or "enlivened presence." This state is usually achieved by "divine remembrance" in the Dhikr by repeating God's names and other Quranic verses (Rauf, 2004).

The psychotherapeutic contributions of medieval Muslims have previously been classified into two major themes. One of these is medieval medical psychotherapy, which was practiced by physicians to help patients with psychological problems (Shafii, 1972). The other type of psychotherapeutic contribution lies in adding aspects of the spiritual practices of certain Muslim sects, and particularly the Sufis, to psychotherapeutic methods that made them more acceptable and more effective with Muslims who follow these sects (Ajmal, 1986). Both these forms of spiritual contribution to psychotherapy are, in many ways, a type of introspection and self-understanding that helps in self-development (Nixon \& Zangeneh, 2012; Shafii, 1985) in a way that helps to make life more meaningful and purposeful by answering existential questions such as "What is the purpose of living?" and "Who am I?" (Diekman, 1977; Shafii, 1985). Clinton (2006) associated Jungian analytic psychology archetypes to the 99 divine names used by Sufis in Dhikr. 
In his account of his childhood in an Egyptian village, Sayyid Qutb (when he was a young writer and before he became a politician) gave a detailed account of the esteem in which Sufi dervishes were held in rural societies then. He described the spiritual healing powers exhibited by these dervishes (Qutb, 1945, pp. 3-7).

Sufism has an important role to contribute to spiritual and mental health. According to Shah (1968),

The Sufi objective is towards the perfecting or completing of the human mind ... that certain kind of mental and other activity can produce under special conditions and with particular efforts, what is termed a higher working of the mind, leading to special perceptions whose apparatus is latent in the ordinary man. Sufism is therefore the transcending of ordinary limitation. (p. 14)

Shah's description of the benefits of mental experiences to Sufis has been associated with the self-growth and personal development experienced on the Sufi path (West, 2004). The possible role of Sufism and other mystical traditions can be of "transformational intensity" when combined with modern psychotherapeutic methods (Nixon \& Zangeneh, 2012). It has been suggested that a therapy which has a spiritual dimension can help heal traumas that obstruct growth and development of clients (West, 2004).

Shafii (1985), in his book Freedom From the Self: Sufism, Meditation, and Psychotherapy, suggested that the therapeutic effect of Sufism is related to answering existential questioning of one's values and reason for being and as a result of self-development through becoming acutely aware of the lack of fulfillment from materialistic goods which do not fulfill the inner spiritual need for harmony (Shafii, 1985). $\mathrm{He}$ also related the therapeutic aspects of Sufism to the psychoanalytical relationship between the seeker (or novice) Sufi and the Sufi sheikh (teacher), which involves the analysis of the murid's (student) life, thoughts, and dreams (Shafii, 1985). However, from its history, the therapeutic effects of Sufism seem to benefit not only the novices but also major philosophers.

Al-Gazali, the famous Muslim philosopher, lived between 1058 and 1111 AD. He described in his book Al-Munqidh min al-Dhalal (The Saver from Error) how he became clinically depressed and that the doctors of his time could not treat him as his illness "was not of the body but of the soul" (Bejou, 1992, p. 64). He stated clearly that embracing Sufism helped him to overcome his depression and to be able to continue his intellectual and philosophical writings (Bejou, 1992, pp. 64-68).

\section{The Way Forward in Integrating EMDR With the Sufi Dhikr}

Many books and articles have been written on the psychotherapeutic aspects of Sufism. Many of these articles have related the psychotherapeutic effects of Sufism to either its spiritual aspects (Bejou, 1992) or to the dynamic aspect of the relationship of the Sufi teacher with the seekers of the path (murad; Diekman, 1977; Shafii, 1985). More recent works have suggested that the therapeutic aspects of Sufism may lie in the movements performed during the Dhikr ritual or service and included in what has been described as the psychocorporal method, a form of movement therapy (Lahore, Griffith, \& Thyloch, 2007).

One important ritual of the Sufis is Dhikr singing and dancing. Our hypothesis is that the Dhikr fulfills functions similar to the stages of EMDR. The Sheik discuss with murids or students their problems, thoughts, emotions, and even dreams, and then the Dhikr is performed by the murids who move their bodies and heads while in a semicircle around the Sheik which may cause eye movement in addition to rhythmic bilateral movements. The Dhikr includes regular movements of the head from right to left which may cause a form of eye movements that cause the therapeutic effects.

The experience of Gordon in treating traumatized people in Gaza by making parallels between Sufi Dhikr and his psychotherapeutic intervention to make it more acceptable to faith-based populations, Gordon's (2006) experience together with our own experience, through the HAP of the EMDR Association UK and Ireland training and supervision of Middle East mental health workers, has inspired us to call for further study of faith-based therapies and therapeutic practices to identify elements involving BLS to use in poor countries where resources are low. The addition of a spiritual dimension to EMDR may further enhance the effectiveness of the therapeutic process in posttraumatic growth, recovery, and increase its acceptability in the Muslim world (Calhoun et al., 2000).

We are recommending future research that could examine whether the head and eye movements during the Dhikr have effects similar to that of eye movements during EMDR. It would also be interesting to investigate the effectiveness and acceptability of treatment combining some of the Dhikr elements with EMDR procedures. 


\section{References}

Abdul-Hamid, W. K. (2011). Thematic paper: The need for a category of 'religious and spiritual problems' in ICD-11. International Psychiatry, 8, 60-61.

Ajmal, M. (1986). Muslim contributions to psychotherapy and other essays. Islamabad, Pakistan: National Institute of Psychology.

Alegría, M., Mulvaney-Day, N., Woo, M., Torres, M., Gao, S., \& Oddo, V. (2007). Correlates of past-year mental health service use among Latinos: Results from the National Latino and Asian American Study. American Journal of Public Health, 97, 76-83.

Al-Faris, E. A. (2000). The pattern of alternative medicine use among patients attending health centres in a military community in Riyadh. Journal of Family \& Community Medicine, 7(2), 17-25.

Arberry, A. J. (1969). Sufism: An account of the mystics of Islam. London, United Kingdom: George Allen \& Unwin.

Azhar, M. Z., Varma, S. L., \& Dharap, A. S. (1994). Religious psychotherapy in anxiety disorder patients. Acta Psychiatrica Scandinavica, 90(1), 1-3.

Barrowcliff, A. L., Gray, N. S., Freeman, T. C. A., \& MacCulloch, M. J. (2004). Eye-movements reduce the vividness, emotional valence and electrodermal arousal associated with negative autobiographical memories. Journal of Forensic Psychiatry and Psychology, 15, 325-345.

Basu, S. (1995). How the spiritual dimension of health was acknowledged by the World Health Assembly-A report. New Approaches to Medicine and Health, 3, 47-51.

Bejou, M. (1992). Al-munqidh min al-dhalal [The saver from error]. Damascus, Syria: Dar al-Taqwa.

Bisson, J., Roberts, N. P., Andrew, M., Cooper, R., \& Lewis, C. (2013). Psychological therapies for chronic posttraumatic stress disorder (PTSD) in adults. Cochrane Database of Systematic Reviews, (12), CD003388. http: / / dx .doi.org/10.1002/14651858.CD003388.pub4

Bradley, R., Greene, J., Russ, E., Dutra, L., \& Westen, D. (2005). A multidimensional meta-analysis of psychotherapy for PTSD. American Journal of Psychiatry, 162(2), 214-227.

Brown, J. P. (1868). The dervishes, or oriental spiritualism. London, United Kingdom: Trubner.

Calhoun, L. G., Cann, A., Tedeschi, R. G., \& McMillan, J. A. (2000). Correlational test of the relationship between posttraumatic growth, religion, and cognitive processing. Journal of Traumatic Stress, 13, 521-527.

Christman, S. D., Garvey, K. J., Propper, R. E., \& Phaneuf, K. A. (2003). Bilateral eye movements enhance the retrieval of episodic memories. Neuropsychology, 17, 221-229.

Clinton, A. (2006). Seemorg matrix work: A new transpersonal psychotherapy. Journal of Transpersonal Psychology, 38(1), 95-116.

Davidson, P. R., \& Parker, K. C. (2001). Eye movement desensitization and reprocessing (EMDR): A metaanalysis. Journal of Consulting and Clinical Psychology, 69(2), 305-316.
Dein, S. (2006). Religion, spirituality and depression: Implications for research and treatment. Primary Care and Community Psychiatry, 11(2), 67-72.

Dervic, K., Grunebaum, M., Burke, A., Mann, J., \& Oquendo, M. (2006). Protective factors against suicidal behavior in depressed adults reporting childhood abuse. The Journal of Nervous and Mental Disease, 194(12), 971-974.

Diekman, A. J. (1977). Sufism and psychiatry. The Journal of Nervous and Mental Disease, 165, 318-329.

Dols, M. W. (1992). Majnun: The madman in medieval Islamic society. Oxford, United Kingdom: Clarendon Press.

Elofsson, U. O. E., von Schèele, B., Theorell, T., \& Söndergaard, H. P. (2008). Physiological correlates of eye movement desensitization and reprocessing. Journal of Anxiety Disorders, 22, 622-634.

Farrukh, O. A. (1981). Islamic mysticism. Beirut, Lebanon: Dar al-Kitab Arabi.

Gail, T., Basque, Y., Damasceno-Scott, M., \& Vardy, O. (2007). Spirituality and the current adjustment of adult survivors of childhood sexual abuse. Journal for the Scientific Study of Religion, 46(1), 101-117.

Gordon, J. (2006). Healing the wounds of war in Gaza and Israel: A mind-body approach. In J. Kuriansky (Ed.), Terror in the Holy Land: Inside the anguish of the IsraeliPalestinian conflict. Westport, CT: Praeger.

Hipolito, E., Samuels-Dennis, J. A., Shanmuganandapala, B., Maddoux, J., Paulson, R., Saugh, D., \& Carnahan, B. (2014). Trauma-informed care: Accounting for the interconnected role of spirituality and empowerment in mental health promotion. Journal of Spirituality in Mental Health, 16(3), 193-217.

Johnsdotter, S., Ingvarsdotter, K., Ostman, M., \& Carlbom, A. (2011). Koran reading and negotiation with jinn: Strategies to deal with mental ill health among Swedish Somalis. Mental Health, Religion \& Culture, 14(8), 741-755.

Johnson, D. M., Worell, J., \& Chandler, R. K. (2005). Assessing psychological health and empowerment in women: The Personal Progress Scale Revised. Women \& Health, 41, 109-129.

Joseph, S. (2009). Growth following adversity: Positive psychological perspectives on posttraumatic stress. Psihologijske Teme, 18, 335-344.

Kuiken, D., Chudleigh, M., \& Racher, D. (2010). Bilateral eye movements, attentional flexibility and metaphor comprehension: The substrate of REM dreaming? Dreaming, 20, 227-247.

Lahore, I., Griffith, E. T., \& Thyloch, E. (2007). Dervishes yoga for health and longevity. Lake Worth, FL: Nicolas-Hays.

Lee, C. W., \& Cuijpers, P. (2013). A meta-analysis of the contribution of eye movements in processing emotional memories. Journal of Behavior Therapy and Experimental Psychiatry, 44(2), 231-239.

Maxfield, L. (2014). Commemorating EMDR's 25th anniversary by highlighting EMDR humanitarian projects. Journal of EMDR Practice and Research, 8(4), $179-180$. 
Maxfield, L., Melnyk, W. T., \& Hayman, C. A. G. (2008). A working memory explanation for the effects of eye movements in EMDR. Journal of EMDR Practice and Research, 2, 247-261.

Meadows, L., Kaslow, N., Thompson, M., \& Jurkovic, G. (2005). Protective factors against suicide attempt risk among African American women experiencing intimate partner violence. American Journal of Community Psychology, 36(1-2), 109-121.

Moreira-Almeida, A., Neto, F., \& Koenig, H. (2006). Religiousness and mental health: A review. Revista Brasileira de Psiquiatria, 28(3), 242-250.

Nicholson, R. A. (1989). The mystics of Islam. London, United Kingdom: Arkana.

Nickelsberg, R., \& Matloff, J. (2009). Faith healing in Kashmir. Retrieved from http:/ / dartcenter.org/tag/sufism

Nixon, G., \& Zangeneh, M. (2012). Editorial: Emerging innovations in counselling and psychotherapy. International Journal of Mental Health and Addiction, 10(3), 309-310.

Nizamie, S. H., Katshu, M. Z., \& Uvais, N. A. (2013). Sufism and mental health. Indian Journal of Psychiatry, 55(Suppl. 2), S215-S223.

Propper, R., Pierce, J. P., Geisler, M. W., Christman, S. D., \& Bellorado, N. (2007). Effect of bilateral eye movements on frontal interhemispheric gamma EEG coherence: Implications for EMDR therapy. Journal of Nervous and Mental Disease, 195, 785-788.

Propst, R. L., Ostrom, R., Watkins, P., Dean, T., \& Mashburn, D. (1992). Comparative efficacy of religious and nonreligious cognitive-behavioral therapy for the treatment of clinical depression in religious individuals. Journal of Consulting and Clinical Psychology, 60, 94-103.

Qutb, S. (1945). A child from a village. Köln, Germany: Al-Kamel.

Rauf, F. A. (2004). What is right with Islam? San Francisco, CA: Harper.

Razali, S. M., Hasanah, C. I., Aminah, K., \& Subramaniam, M. (1998). Religious-sociocultural psychotherapy in patients with anxiety and depression. Australian and New Zealand Journal of Psychiatry, 32(6), 867-872.

Saeed, K., Gater, R., Hussain, A., \& Mubbashar, M. (2000). The prevalence, classification and treatment of mental disorders among attenders of native faith healers in rural Pakistan. Social Psychiatry and Psychiatric Epidemiology, 35, 480-485.

Shafii, M.(1972). A precedent for modern psychotherapeutic techniques: One thousand years ago. The American Journal of Psychiatry, 128(12):1581-1584.

Shafii, M. (1985). Freedom from the self: Sufism, meditation, and psychotherapy. New York, NY: Human Sciences Press.

Shah, A. (1968). The way of the Sufi. London, United Kingdom: Octagon Press.

Shapiro, F. (1989). Efficacy of the eye movement desensitization procedure in the treatment of traumatic memories. Journal of Traumatic Stress, 2, 199-233.
Shapiro, F. (2001). Eye movement desensitization and reprocessing (EMDR): Basic principles, protocols and procedures (2nd ed.). New York, NY: Guilford Press.

Shapiro, F. (2007). EMDR, adaptive information processing, and case conceptualization. Journal of EMDR Practice and Research, 1, 68-87.

Shapiro, F. (2012). EMDR therapy training manual. Watsonville, CA: EMDR Institute.

Shapiro, F. (2014). The role of eye movement desensitization and reprocessing (EMDR) therapy in medicine: Addressing the psychological and physical symptoms stemming from adverse life experiences. The Permanente Journal, 18(1), 71-77.

Sahrwardi, U. M. (1980). A dervish textbook from the 'Awarifu1-Ma'arif written in the thirteenth century $(\mathrm{H}$. W. Clarke, Trans.). London, United Kingdom: Octagon Press.

Tolson, J. (2008). Paying attention to the "other Islam" The moderate voices of the Sufi tradition. Retrieved from http: / / www.usnews.com/news / articles / 2008/08/20/ paying-attention-to-the-other-islam

Van den Hout, M. A., \& Engelhard, I. M. (2012). How does EMDR work? Journal of Experimental Psychopathology, 3(5), 724-738.

van den Hout, M., Rijkeboer, M. M., Engelhard, I. M., Klugkist, I., Hornsveld, H., Toffolo, M. J., \& Cath, D. C. (2012). Tones inferior to eye movements in the EMDR treatment of PTSD. Behaviour Research and Therapy, 50, 275-279.

van der Kolk, B. A., Spinazzola, J., Blaustein, M. E., Hopper, J. W., Hopper, E. K., Korn, D. L., \& Simpson, W. B. (2007). A randomized clinical trial of eye movement desensitization and reprocessing (EMDR), fluoxetine, and pill placebo in the treatment of posttraumatic stress disorder: Treatment effects and long-term maintenance. The Journal of Clinical Psychiatry, 68(1), 37-46.

Vaughan-Lee, L. (1990). The lover and the serpent: Dreamwork within a Sufi tradition. Shaftesbury, United Kingdom: Element Books.

West, W. (2004). Humanistic integrative spiritual psychotherapy with a Sufi convert. In P. R. Richards \& A. E. Bergin (Eds.), Casebook for a spiritual strategy in counseling and psychotherapy (pp. 201-212). Washington, DC: American Psychological Association.

Wong, J., Rew, L., \& Slaikeu, K. (2006). A systematic review of recent research on adolescent religiosity/spirituality and mental health. Issues in Mental Health Nursing, 27(2), 161-183.

World Health Organization. (2013). Guidelines for the management of conditions specifically related to stress. Geneva, Switzerland: Author.

Yoon, D., \& Lee E. (2007). The impact of religiousness, spirituality and social support on psychological well being among older adults in rural areas. Journal of Gerontological Social Work, 48(3/4), 281-298.

Correspondence regarding this article should be directed to Walid Khalid Abdul-Hamid, Centre for Psychiatry, Barts and the London School of Medicine and Dentistry, Queen Mary University of London; Linden Centre, Broomfield, Chelmsford CM1 7LF, United Kingdom. E-mail: walid.abdulhamid@nhs.net 